\title{
Juventudes, Estado e Povos Indígenas no Brasil do Século XXI
}

\author{
Assis da Costa Oliveira, lic. \\ Universidade Federal do Pará, Brasil*
}

assisdco@gmail.com

\section{Resumo (descritivo)}

O presente artigo objetiva analisar o processo de construção da juventude como uma causa de interesse público-estatal no Brasil, com emergência histórico-temporal nas duas décadas iniciais do Século $X X I$. Ao mesmo tempo, busca-se compreender como as juventudes indígenas desenvolveram suas mobilizações político-organizacionais para galgar reconhecimento identitário, lutas sociais e direitos específicos. Com base em pesquisa bibliográfica, entrevistas e observação participante, procura-se analisar as oportunidades políticas surgidas no governo federal para inclusão da juventude, além de problematizar o modo como as juventudes indígenas constroem cenários mobilizatórios de interpelação do juvenil e do étnico, constituindo um novíssimo movimento social que instrumentaliza os espaços físicos e virtuais, o corpo e o capital militante para incidência política de suas demandas por direitos.

\section{Palavras-chave}

Jovens, povos indígenas, participação social, política pública, movimentos sociais.

\section{Thesauro}

Tesauro de Ciencias Sociales de la Unesco.

\section{Para citar este artículo}

Oliveira, A. C. (2020). Juventudes, Estado e Povos Indígenas no Brasil do Século XXI. Revista Latinoamericana de Ciencias Sociales, Niñez y Juventud, 18(1), 1-25. http://dx.doi.org/ $10.11600 / 1692715 \times .18105$

\section{Historial}

Recibido: 23.04.2019

Aceptado: 23.07.2019

Publicado: 25.11.2019

Información artículo

Este artigo de reflexão se baseia na investigação denominada «Juventude Indígena, Mobilização Social e Direitos Humanos: Subsídios para compreensão dos direitos da juventude indígena no Brasil», realizada pelo autor no doutorado em Direito na Universidade de Brasília e com apoio da Coordenação de Aperfeiçoamento de Pessoal de Ensino Superior (Processo No 88881.187039/ 2018-01), iniciada em março de 2016 e ainda em andamento. Apesar de formalmente iniciada em março de 2016, o levantamento de dados da pesquisa começou em agosto de 2015. Área: Ciências Sociais. Subárea: Direito. 


\section{Youth, State and Indigenous People in Brazil in the 2Ist Century}

\section{Abstract (descriptive)}

This article analyzes the process of the construction of youth as a cause of public and state interest in Brazil during the first two decades of the 21st Century. At the same time, the study enquires about how indigenous youth in Brazil have developed their political and organizational mobilization to ensure identity recognition, social struggles and guarantee specific rights. Based on bibliographic research, interviews, and participant observation, the study analyzes the political opportunities in the federal government for the inclusion of youth, as well as examining the way in which indigenous youth have constructed mobilization scenarios to bring together youth and ethnic issues. These social movements have been defined as a «new new» social movement that uses physical and virtual spaces, youth bodies and militant capital to engage in political advocacy and demand their rights.

Keywords

Youth, indigenous people, social participation, public policy, social movement.

\section{Juventudes, Estado y pueblos indígenas de Brasil en el Siglo XXI}

\section{Resumen (descriptivo)}

El presente artículo tiene como objetivo analizar el proceso de construcción de la juventud como una causa de interés público-estatal en Brasil, con emergencia histórico-temporal en las dos primeras décadas del Siglo XXI. Al mismo tiempo, busca comprender cómo las juventudes indígenas desarrollarán sus movilizaciones político-organizacionales y acciones colectivas para lograr reconocimiento identitario, luchas sociales y derechos específicos. Con base en la investigación bibliográfica, entrevistas y observación participante, se procura analizar las oportunidades políticas surgidas en el gobierno federal para la inclusión de la juventud, además de problematizar el modo como las juventudes indígenas construyen escenarios movilizatorios de interpelación juvenil y étnica, constituyéndose en un novísimo movimiento social que instrumentaliza los espacios físicos y virtuales, el cuerpo y el capital militante para la incidencia política de sus demandas por derechos.

\section{Palabras clave}

Jóvenes, pueblos indígenas, participación social, políticas públicas, movimientos sociales.

\section{Información autor}

[*] Advogado. Doutorando pelo Programa de Pós-Graduação em Direito da Universidade de Brasília. Mestre pelo Programa de Pós-Graduação em Direito da Universidade Federal do Pará (UFPA). Bacharel em Direito pela UFPA. Professor da Faculdade de Etnodiversidade da UFPA, Campus de Altamira. (iD) 0000-0003-3207-7400. Índice H5: 1. Correio eletrônico: assisdco@gmail.com 


\section{Introdução}

O presente artigo objetiva analisar o processo de construção da juventude como uma causa de interesse público-estatal no Brasil, com emergência histórico-temporal nas duas décadas iniciais do Século XXI. Ao mesmo tempo, busca empreender a compreensão de como um dos ramos da juventude, a relacionada aos povos indígenas, desenvolveu suas mobilizações político-organizacionais e ações coletivas no mesmo período, para galgar reconhecimento identitário, lutas sociais e direitos específicos.

Procuro demonstrar o caminho sócio-institucional de visibilização/atendimento da juventude como foco de atenção de políticas públicas e espaços institucionais estatais, além de problematizar o modo como as juventudes indígenas constroem cenários mobilizatórios de interpelação do juvenil no étnico, e do étnico no juvenil, constituindo-se num novíssimo movimento social que instrumentaliza os espaços físicos e virtuais, o corpo e o capital militante para incidência política de suas demandas por direitos.

O artigo está organizado em duas seções gerais, com suas respectivas subseções. A primeira parte discute o legado político, normativo e institucional da pauta da juventude no Brasil, relacionando-o com indicadores de educação, violência e suicídio, para compreender os ganhos e as omissões destas políticas para o campo da diversidade étnicorracial. Na segunda parte, a análise centra-se na mobilização político-organizacional nacional das juventudes indígenas, partindo da compreensão de sua emergência temporal e formas de institucionalidade, para depois discutir fatores que fomentaram tal emergência, o modo como podem ser compreendidos como novíssimo movimento social, além do processo de apropriação do corpo e das redes sociais digitais para condução de suas ações militantes.

\section{Metodologia}

A coleta dos dados foi realizada com base nos métodos da pesquisa bibliográfica, observação participante e entrevista. Desde 2015 desenvolvo pesquisa sobre a ação cole- 
tiva das juventudes indígenas no Brasil para a participação e a incidência política nos espaços de tomada de decisão sobre políticas públicas e direitos nos campos institucionais da juventude e dos povos indígenas, além de outros em que estes temas são tratados de maneira transversal.

A pesquisa bibliográfica vem sendo desenvolvida com base na coleta de documentos normativos e institucionais relacionados à juventude e aos povos indígenas, e pesquisas interdisciplinares sobre políticas de juventude no Brasil e na América Latina. Além de estudos sobre juventudes indígenas no Brasil, os quais, como apontam Oliveira e Rangel (2017) e Oliveira (2019), são de recente interesse acadêmico no país e ainda restrito à poucas áreas (Antropologia, Educação e História, sobretudo), cujo aumento e diversificação das pesquisas estão relacionados à ampliação da visibilidade e atuação das juventudes indígenas nos espaços sociais, e a implantação das políticas públicas direcionadas à este público.

A observação participante e as entrevistas foram conduzidas majoritariamente pela escolha metodológica de acompanhar eventos públicos de discussão sobre políticas públicas e direitos em que as jovens e os jovens indígenas participam como sujeitos sociais. Por isso, trabalho com a descrição da ação coletiva em si que produzem e da reflexão que possuem sobre as ações desenvolvidas. No entanto, no presente artigo, os dados que utilizo são mais da descrição e análise das ações coletivas desenvolvidas, e menos das entrevistas dos sujeitos. Uma segunda opção metodológica é o acompanhamento da articulação político-organizacional das juventudes indígenas na Comissão Nacional de Juventude Indígena (CNJI) e na Rede de Juventude Indígena (Rejuind), esta última via redes sociais digitais, como o Facebook.

Os dados coletados para o presente artigo possuem um período temporal fixado entre os anos de 2005 e 2015, justamente o que é reconhecido como o de maior incidência da juventude como uma causa de interesse público-estatal (Freitas, 2019; Guaraná de Castro \& Macedo, 2019).

\section{Brasil e as políticas de juventude(s)}

A emergência da juventude como uma causa pública no Brasil —é dizer, como uma «causa militante que promueve adhesiones y movilización» (Vázquez, 2013, p. 4)— possui um marcador político-temporal relacionado aos governos de esquerda de Lula e Dilma (2003-2016), que engendraram a adoção de políticas públicas e estruturas institucionais 
relacionadas à condição juvenil, concomitante ao fortalecimento da incidência política das ações coletivas de grupos juvenis —e também de militância juvenil dentro do Estado (Vázquez, 2013), com a institucionalização de mecanismos de participação e controle social da gestão governamental.

De acordo com Rodríguez (2015), que estruturou o Índice de Desenvolvimento das Políticas Setoriais de Juventude para a América Latina, ${ }^{1}$ numa análise comparativa dos países da região, o Brasil ocupa a $2^{\underline{a}}$ colocação $(0,68513)$ no Índice 1 e a $1^{\underline{a}}$ posição (o.45261) no Índice 2. De início, cabe enfatizar, igual indica o autor, que o mais relevante é perceber «el bajo nivel de desarrollo de políticas sectoriales de juventud verificado por esta via en todos los países de la región» (2015, p. 21), ao que é preciso reiterar que mesmo estando entre os melhores índices entre os países pesquisados, a pontuação brasileira, assim como a dos demais países, ainda está abaixo de um nível satisfatório.

No entanto, há um contexto histórico que ajuda a entender a sedimentação das bases da atenção que as políticas setoriais de juventudes tiveram no Brasil. Segundo Abramo (2011), foi no início dos anos 2000, mais precisamente em 2005, com o surgimento da Secretaria Nacional de Juventude (SNJ), do Conselho Nacional de Juventude (Conjuve) e do avanço da proposta legislativa (Projeto de Lei ${ }^{\circ}$. 4530/2004) da Política Nacional de Juventude (PNJ), que se abriu espaço estatal para problematização das vulnerabilidades e demandas juvenis. Isto, combinado ao engajamento de novos agentes e coletivos juvenis que passaram a instrumentalizar a linguagem dos direitos para o planejamento, implantação e avaliação de políticas públicas.

Deve-se compreender tais estruturas estatais de institucionalização das políticas públicas e participação social das juventudes como parte do «ciclo político»² (Unda-Lara,

\footnotetext{
${ }^{1} \mathrm{O}$ Índice possibilita a avaliação comparada das políticas setoriais de juventude com base em indicadores relacionados à educação, trabalho, educação e trabalho (combinados), saúde, violências e participação cidadã, de modo a reunir dados nacionais de 18 países latino-americanos. Com isso, Rodríguez (2015) padronizou os dados coletados via indicadores numa escala de o a 1, de modo a gerar duas versões de índices: «por un lado, el Índice 1 incluye el promedio simples de cada indicador (ponderación implícita), considerando la cantidad de variables de las que cada país cuenta con información (varía de 14 a 16). Por su parte, el Índice 2 incluye el promedio ponderado, donde cada dimensión adquiere un peso específico: educación ( $24 \%)$, inserción laboral (24\%), educación y trabajo (4\%), salud (18\%), violencia (18\%) y participación ciudadana (12\%)» (2015, pp. 5-6).

${ }^{2}$ Nesse sentido, faço uso da definição de ciclo político de Unda-Lara, de «categoría útil para la comprensión de las formas - y repertorios- de acción colectiva que (re)aparecen, se mantienen, transforman o emergen en un determinado contexto sociopolítico en el que se ha producido modalidades de participación de diversas formas asociativas juveniles (FAJ) caracterizadas por movilizaciones de distinto tipo y cuyo eje dinamizador común es el conflicto en sus diversas manifestaciones» (2016, p. 1).
} 
2016) estabelecido no período dos governos de esquerda de Lula e Dilma, em que um repertório de ações e demandas coletivas das juventudes encontra receptividade e atendimento por parte do Estado. Nesse sentido, trata-se de um ciclo político que está imbricado à chegada na Presidência da República de um partido de esquerda, o Partido dos Trabalhadores (PT), que passa a impulsionar espaços de democracia participativa, especialmente os conselhos deliberativos e as conferências, assim como oportuniza uma abertura de diálogo institucional com os movimentos sociais juvenis -isto, certamente, não se estabelece como abertura voluntária dos agentes estatais, mas devido à pressão e mobilização dos movimentos sociais.

Estas estruturas institucionais e políticas públicas de âmbito nacional foram depois incorporadas pelos estados e municípios brasileiros, replicando o formato de organização estatal. No entanto, há de se considerar um déficit de garantia da universalidade a todos os entes de governos de estados e de municípios, pois apesar do fortalecimento das pautas das juventudes no governo federal, o mesmo não foi acompanhado nos outros níveis da gestão estatal, especialmente naqueles locais governados por partidos políticos de direita e centro-direita. Isto porque, dado o acesso institucional e a mobilização social que as demandas das juventudes, e de outros grupos classificados de «minorias sociais», tiveram nos governos federais do PT, estas acabaram se cristalizando no imaginário sociopolítico como uma «pauta de esquerda».

Em 2010, com a edição da Emenda Constitucional no. 65, que alterou o texto do artigo $227^{3}$ da Constitucional Federal de 1988, passou-se a incluir a juventude como destinatária da mesma Doutrina da Proteção Integral formulada às crianças e aos adolescentes, obtendo dois ganhos substanciais: (1) assegurar às juventudes as mesmas condições de tratamento jurídico ofertado às crianças e aos adolescentes, especialmente em relação à garantia da prioridade absoluta ${ }^{4}$ de cumprimento dos seus direitos, de modo a estabelecer um patamar de valorização jurídica até maior que o plano internacional dos direitos da

${ }^{3}$ O texto passou a ser este com a alteração feita pela emenda: «Art. 227. É dever da família, da sociedade e do Estado assegurar à criança, ao adolescente e ao jovem, com absoluta prioridade, o direito à vida, à saúde, à alimentação, à educação, ao lazer, à profissionalização, à cultura, à dignidade, ao respeito, à liberdade e à convivência familiar e comunitária, além de colocá-los a salvo de toda forma de negligência, discriminação, exploração, violência, crueldade e opressão» (Brasil, 2010. Itálicos nosso).

${ }^{4}$ Como explicam Silveira e Veronese: «[e]sse princípio veio ajustar a legislação brasileira aos Tratados e às Convenções Internacionais, das quais o Brasil era signatário [...] Portanto, o princípio da prioridade absoluta dos direitos da criança e do adolescente determina [...] a primazia incondicional dos interesses e direitos relativos à infância e à juventude» (2015, p. 116). 
juventude; 5 (2) obrigação de implantar uma regulamentação jurídica infraconstitucional para os direitos das juventudes, concretizada em 2013 com a edição do Estatuto da Juventude (Lei noํ. 12.852/2013), e a previsão de elaboração de novo Plano Nacional de Juventude, agora de caráter decenal, ${ }^{6}$ até o momento não efetivado.

O Estatuto da Juventude formulou as bases do Sistema Nacional de Juventude (Sinajuve), mecanismo de articulação entre as diferentes esferas do Estado, com a participação da sociedade civil, para a promoção das políticas públicas de juventude. No entanto, somente com o Decreto n⿳⺈.9.306/2018 o Sinajuve foi regulamentado e, como observam Guaraná de Castro e Macedo (2019), com uma fragilidade estrutural ao não prever a obrigatoriedade do financiamento das políticas, pois indica que dependerá de «transferências voluntárias» e de «disponibilidade de recursos» no orçamento público para sua implementação.?

Desde uma leitura de Tarrow (1999), compreendem-se estes elementos como «estruturas de oportunidades políticas», no sentido de

señales continuas - aunque no necesariamente permanentes, formales o a nivel nacional- percibidas por los agentes sociales o políticos que les animan o desaniman a utilizar los recursos con los que cuentan para crear movimientos sociales. (1999, p. 89)

\footnotetext{
${ }^{5}$ No âmbito dos tratados internacionais de direitos humanos, o documento jurídico com maior força obrigacional é a Convenção Iberoamericana de Direitos dos Jovens, elaborada em 2005 pela Organização Iberoamericana de Juventude, mas só ratificada pelo Brasil em 2014, ainda assim com um tratamento jurídico à juventude que não the reconhece o mesmo patamar de prioridade dos direitos assegurado às crianças e aos adolescentes em relação à Convenção dos Direitos da Criança, de 1989, elaborada pela Organização das Nações Unidas.

6 Tais dispostos conforme o artigo 227, parágrafo $8^{\circ}$ da Constituição Federal de 1988, nos seguintes termos: «A lei estabelecerá: I - o estatuto da juventude, destinado a regular os direitos dos jovens; II - o plano nacional de juventude, de duração decenal, visando à articulação das várias esferas do poder público para a execução de políticas públicas» (Brasil, 2010).

7 Trata-se da análise de Guaraná de Castro e Macedo (2019) aos artigos 15 e 16 do Decreto que regulamenta o Sinajuve, e que estão assim definidos: «Art. 15. A Secretaria Nacional de Juventude da Secretaria de Governo da Presidência da República fornecerá os recursos humanos, tecnológicos e orçamentários para a implementação, a manutenção e a operacionalização da Plataforma virtual interativa, do Subsistema de Informação, Monitoramento e Avaliação e do Cadastro Nacional de Unidades de Juventude, observada a disponibilidade orçamentária e financeira [...] Art. 16. As transferências voluntárias de recursos públicos federais, no âmbito da dotação orçamentária da Secretaria Nacional de Juventude da Secretaria de Governo da Presidência da República, para apoio à promoção das políticas públicas de juventude, priorizarão os entes federativos que aderirem ao Sinajuve» (Brasil, 2018. Itálicos nossos).
} 
As oportunidades políticas descritas acima - de cunho político, institucional e normativo- redefiniram as formas de ação coletiva dos movimentos sociais juvenis para destinar uma boa dose de seus recursos militantes à interlocução e participação direta nos espaços institucionais criados, em nível nacional, estadual e municipal. Com uso dos três tipos básicos de repertório de ação coletiva ${ }^{8}$ definidos por Revilla-Blanco (2010), pode-se identificar o uso hegemônico, neste período do Brasil, de movimentos juvenis categorizados como «ação coletiva contida» (acción colectiva contenida), de certo modo levando à «normalização dos meios de ação» (Revilla-Blanco, 2010) que tivessem por base o protesto e a confrontação pelas vias dos canais institucionais estabelecidos pelo Estado.

Mas também, deve-se sublinhar o ativismo social, travestido em diversas mobilizações político-organizacionais, desenvolvidas por segmentos da juventude brasileira ao longo desse período, e que tiveram na realização da $1^{\underline{a}}, 2^{\underline{a}}$ e $3^{\underline{a}}$ Conferências Nacionais da Juventude, nos anos de 2008, 2011 e 2015, respectivamente, os principais momentos de convergência de ações coletivas para evidenciar o protagonismo das organizações de juventude, assim como a execução cotidiana do Conjuve, um dos conselhos setoriais mais atuantes no Brasil.

Isto, por certo, precisa ser relativizado ante a ocorrência dos protestos nacionais de junho e julho de 2013, no contexto de realização da Copa das Confederações no Brasil, quando a utilização da violência —em parte dos atos promovidos e como reação à violência policial — associado à instrumentalização da mobilização em massa via articulação por redes sociais digitais, tinham um foco comum de questionamento do sistema político brasileiro e do modelo de desenvolvimento econômico. E, com isso, implica compreender que mesmo as gestões governamentais do PT não conseguiram reduzir as desigualdades sociais e os usos particulares dos bens públicos, expressando as limitações dos avanços políticos e sociais vividos nos últimos anos (Gohn, 2014; Vommaro, 2015), inclusive no âmbito das políticas setoriais de juventudes.

\footnotetext{
${ }^{8}$ Revilla-Blanco (2010) estabelece três tipos básicos repertórios de ação coletiva: a primeira, definida como ações coletivas contidas, representa um conjunto de ações de baixo ou escasso risco e que tampouco necessita de grande investimento de compromisso dos executantes, sendo também aceitas pelas autoridades, como as campanhas, os manifestos, as marchas e as greves; a segunda, ações coletivas de confrontação, implica «cierto riesgo de alteración del orden público o de uso de la violencia (daños contra la propiedad)» (2010, p. 57), além de exigirem um modo de organização, de benefícios e de custos assumidos pelo grupo, como as greves de fome, as ocupações de edifícios e os boicotes; por fim, a última categoria, as ações coletivas de violências, é o uso da violência contra determinadas pessoas como meio da ação coletiva, a exemplo dos conflitos armados, do terrorismo e da guerrilha.
} 


\section{Indicadores sociais brasileiros de políticas setoriais de juventudes}

\section{e o tratamento da diversidade do «ser jovem»}

Depois de discutir a formação das estruturas políticas, institucionais e normativas relacionadas às juventudes no Brasil, é interessante analisar os indicadores nacionais que Rodríguez (2015) utiliza como dados para a estruturação dos índices anteriormente informados, verificando os dados mais relevantes das políticas setoriais de juventude no contexto brasileiro.

Quanto aos dados de educação, percebe-se que o Brasil é o $8^{a}$ país com maior porcentagem de acesso de jovens à educação primária, com $95.7^{\%}$, mas o $5^{\underline{a}}$ pior em acesso da população juvenil à educação superior, com 5.7\% (Rodríguez, 2015), isto entre os 18 países latino-americanos pesquisados. Não se deve deixar de reconhecer, como fazem Clacso e Unesco (2013), a existência de políticas bem sucedidas nacionalmente no período de levantamento dos dados, como exemplos: o Programa Universidade para Todos (Prouni); as políticas afirmativas nas modalidades de cotas, reservas de vagas e cursos especiais para ingresso nas universidades públicas; além do Programa de Reestruturação e Expansão das Universidades Federais (Reuni). Estas políticas conseguiram ampliar o acesso ao ensino superior, especialmente às camadas populares, aos negros e aos povos indígenas, mas cujo grau de beneficiários é ainda bem reduzido numa análise geral da quantidade de jovens, revelando que a exclusão educacional, além de ser uma demanda histórica, exige a adoção de outras políticas públicas para a efetiva superação das barreiras estruturais de impedimento do acesso à grande parcela da população juvenil.

Em relação aos indicadores de violência, segundo Rodríguez (2015), o Brasil é o $4^{\underline{a}}$ país com maior taxa de homicídio entre jovens de 15 a 24 anos, com 52.4 mortes a cada 100 mil habitantes, dentro da análise comparativa entre os 18 países latino-americanos. É importante ressaltar que a base de dados de análise do autor é do período de 2008 a 2010. No Mapa da Violência de 2014, Waiselfisz (2014), com dados obtidos até 2012, indica que a taxa de homicídio subiu para 57.6 para cada 100 mil habitantes, continuando bastante desproporcional a relação entre morte de jovens e de não jovens, ${ }^{9}$ pois «foram vítimas de homicídio por AF [Armas de Fogo] perto de quatro vezes mais jovens que não jovens: a cada não jovem morrem, proporcionalmente, perto de quatro jovens» (Waiselfisz, 2015, p. 67). E as taxas são ainda mais desiguais para os jovens negros homens, as principais vítimas da violência letal na população juvenil. Waiselfisz, ao analisar as taxas

\footnotetext{
9 Pessoas compreendidas abaixo de 15 anos e acima de 30 anos, pois, no Brasil, usa-se a faixa etária de 15 e 29
} anos para a definição político-normativa da juventude. 
anuais de homicídio de jovens entre 2002 e 2012, aponta que «[o] número de homicídios de jovens brancos cai $32.3 \%$, e dos jovens negros aumenta $32.4 \%$ (2014, p. 152). Logo, as taxas gerais nacionais de homicídio acabam por diluir a alta vulnerabilidade que os jovens negros possuem.

Por outro lado, em relação às taxas de suicídio, se bem tem o Brasil uma das menores taxas entre os 18 países latino-americanos, de 6.7\%, como aponta Rodríguez (2015), Verdum (2011) nos lembra que para determinados jovens indígenas esta taxa é bem superior, principalmente os pertencentes aos povos indígenas localizados no hoje estado do Mato Grosso do Sul, cuja taxa de suicídio, em 2011, chegou a 166 suicídios por grupo de 100 mil indígenas, mais de 34 vezes a média nacional à época. O contexto desta «calamidade étnica» de suicídios está relacionado às negligencias estatais para demarcação de terras indígenas, assim como a ausência de recursos básicos para subsistência física e social, gerando um esgotamento dos horizontes de vida para muitos jovens indígenas que usam do suicídio como último recurso de contestação às múltiplas formas de violências e discriminações.

Isto revela que tratar a avaliação das políticas públicas somente com indicadores de abordagem geral da juventude acaba desconsiderando as situações específicas vivenciadas pela diversidade das expressões de «ser jovem» no Brasil, com cenários de afetação desigual por problemas sociais e pela atuação do Estado. Nisso, a análise das juventudes indígenas, e de suas ações coletivas e formas de participação no Estado, contribui para delinear melhor o campo de recepção (ou não) pelas políticas públicas e a lógica de auto-organização.

\section{Juventudes indígenas: entre emergências públicas, militâncias e mobilizações sociais}

No Brasil, desde 2009 ocorre um processo étnico de mobilização político-organizacional de indivíduos que se auto-identificam como «jovens» no contexto dos povos indígenas (Oliveira, 2017). Com a realização do I Seminário Nacional de Juventude Indígena, no referido ano, em Brasília/DF, houve uma primeira articulação de jovens de diferentes povos indígenas que estabeleceram a estratégia de criação de duas instâncias nacionais de auto-organização das juventudes indígenas.

A CNJI, contendo, inicialmente, 15 membros titulares e 15 suplentes contemplando as cinco regiões do país (Norte, Nordeste, Centro-Oeste, Sudeste e Sul), depois reformulada, no II Seminário Nacional da Juventude Indígena, realizado em Goiânia/GO, em 2012, 
para 2 membros por região, num total de 10 pessoas, com a finalidade de «mobilização e articulação da juventude indígena para formação em temas que tratam dos direitos conquistados pelos povos indígenas» (Rejuind, 2014, p. 11). E a Rejuind, página no Facebook ${ }^{10}$ criada e administrada por jovens indígenas para «dialogar e trocar experiências com os povos indígenas, utilizando novas ferramentas, como as redes sociais como espaço de demonstração de ações da juventude indígena [em] prol dos direitos dos povos indígenas» (Rejuind, 2014, p. 13).

Com isso, as juventudes indígenas passaram a se organizar de forma física e virtual para tencionar a participação em espaços estratégicos, obtendo a inserção de representantes no Conjuve, na Comissão Nacional dos Povos Indígenas (CNPI) e nas organizações indígenas de caráter regional e/ou nacional, como a Articulação dos Povos Indígenas do Brasil (Apib), a Coordenação das Organizações Indígenas da Amazônia Brasileira (Coiab) e a Articulação das Organizações Indígenas do Nordeste, Minas Gerais e Espírito Santo (Apoinme), sendo estas as maiores organizações indígenas do Brasil e que passaram a estruturar diretorias ou departamentos específicos para tratar de assuntos voltados às juventudes indígenas.

Por outro lado, a página da Rejuind tem mais de 13 mil pessoas que a seguem, tendo exercido um papel fundamental em 2012, em conjunto com a página Aty Guasu (da juventude Guarani-Kaiowá), na viralização da campanha de sensibilização da sociedade sobre a violência cometida contra o povo Guarani-Kaiowá no estado do Mato Grosso do Sul. Isto gerou uma onda de mudança de sobrenome das pessoas em seus perfís pessoais no Facebook para incluir «Guarani-Kaiowá» e a disseminação de informações pela hashtag \#somostodosguaranikaiowá. Ações como esta impulsionaram o reconhecimento nacional e internacional das juventudes indígenas, tendo, inclusive, o grupo que gerencia a Rejuind passado a atuar em articulações internacionais com juventudes indígenas de outros países, por meio da participação na Red de Juventud Indígena en América Latina e no Global Indigenous Youth Caucus, entre outros espaços sócio-institucionais.

O que chama atenção é a forma como as juventudes indígenas no Brasil, principalmente articuladas na CNJI e na Rejuind, desenvolvem diversas ações militantes para apoio às lutas históricas dos povos indígenas (terra, meio ambiente, conhecimentos tradicionais, etc.), mas também para reconhecimento das especificidades geracionais nas

${ }^{10}$ Acessível pelo link https://www.facebook.com/rejuind/?fref=ts 
relações socioculturais com seus grupos de pertença, assim como no campo das políticas indígenas, indigenistas e juvenis.

Neste caso, há uma evidente politização da condição juvenil em contextos indígenas, de modo a problematizar aspectos das tradições e das organizações sociais que geram barreiras para a inclusão sociopolítica das juventudes nos espaços comunitários, a fim de desconstruir as facetas do adultocentrismo reproduzidas nas práticas sociais locais e justificadas (ou naturalizadas), até certo ponto, como «elementos culturais». E, no âmbito das políticas indígenas e indigenistas, também apontando a necessidade de valorização e reconhecimento de conteúdos específicos de caráter geracional que atendam as demandas das juventudes indígenas.

Por outro lado, esta ação militante das juventudes indígenas também direciona investimento político-discursivo à visibilidade e ao reconhecimento das especificidades étnicas no território político, normativo e institucional das políticas de juventudes. Aqui, o mote central está na denúncia às formas político-estatais de invisibilizar, inferiorizar e/ou exterminar as juventudes indígenas, quase sempre pensando estas questões em articulação com os danos causados às suas coletividades étnicas de pertença, de modo a propor o anúncio de reivindicações para a incorporação da pluralidade étnica do «ser jovem» como elemento estrutural da construção e implementação de políticas públicas, direitos e ações governamentais.

Nesse caso, um dos focos instrumentais de incidência política das juventudes indígenas no campo juvenil, é fazer com que - tal como analisa Oliveira (2016) para o cenário das crianças indígenas e a interpelação indígena à sua proteção para com o Estado brasileiro- um conjunto de órgãos públicos e agências sociais sejam responsabilizadas a se envolverem com suas demandas de caráter coletivo e estrutural, como às ligadas à terra e ao meio ambiente, de modo a ampliar o grupo de apoiadores, ao menos em termos da pretensão reivindicatória.

Estas duas bases de ação militante (do juvenil no étnico e do étnico no juvenil) estão constantemente entrecortadas com demandas de caráter de gênero, sexualidade, pessoa com deficiência, entre outros marcadores sociais, revelando que a diversidade interna das juventudes indígenas, e de suas demandas sociais, é constituída por uma multiplicidade de elementos identitários e de opressões sociais articulados de maneira interseccional. 


\section{Fatores históricos de fomento à emergência político- organizacional nacional das juventudes indígenas}

A emergência nacional das juventudes indígenas é fruto de um histórico de mobilização social e aproveitamento militante de recursos socioestatais. Para compreender tal contexto, é necessário retomar o conceito de oportunidade política de Tarrow (1999) para delinear a análise histórica das bases que possibilitaram a emergência nacional da juventude indígena.

Uma primeira estrutura de oportunidade política, advinda do Estado brasileiro e que influenciou na mobilização, organização e profissionalização das juventudes indígenas, foi a implantação de políticas afirmativas de inclusão universitária para estudantes indígenas, a partir de 2002, o que levou a que milhares de jovens indígenas - atualmente, cerca de 56 mil (Inep, 2018) - pudessem acessar a universidade e desenvolver ações coletivas com base na categoria política de «estudante universitário indígena», as quais depois ressoaram e se ampliaram para a mobilização/articulação enquanto «juventudes indígenas» (Rangel, 2015).

Nisso, desenvolveu-se um crescente cenário de problematização política do estar na universidade, no sentido de discutir a permanência estudantil como um direito —no caso, um direito dos povos indígenas à educação diferenciada, no mesmo sentido pontuado por Langer (2014) para com os estudantes situados em bairros pobres da Argentina-e que implica dois movimentos complementares.

Um primeiro, ligado à reconstrução da racionalidade administrativa, epistemológica e pedagógica da universidade, sobretudo em relação às condições de diálogo, participação e permanência dos estudantes indígenas e, com isso, de visibilização das discriminações e desigualdades que permanecem e se acentuam entre os estudantes indígenas e as demais pessoas não-indígenas que atuam na comunidade acadêmica (Oliveira, Beltrão, \& Domingues, 2015).

E, um segundo, da auto-organização dos estudantes indígenas no espaço universitário, a exemplo do que ocorreu na Universidade Federal do Pará (UFPA), em que a Associação dos Estudantes Indígenas da UFPA (Apyeufpa), criada em dezembro de 2011, passou a potencializar a visibilidade do «ser indígena» e o protagonismo dos estudantes indígenas na condução de ações e eventos dentro e fora da UFPA para discutir as condições de produção de uma universidade mais adequada à diversidade cultural e as formas de materialização dos direitos indígenas nela e fora dela (Fernandes, Beltrão, \& Oliveira, 2015). 
A ampliação do acesso à educação formal, especialmente à universidade, se converte num aspecto relevante de configuração das carreiras dos militantes das juventudes indígenas. Com base em Poupeau (2007), pode-se conceber este processo de estar na universidade como um aspecto relevante do capital militante das e dos jovens indígenas, tornandose um espaço de obtenção de um «saber-fazer adquirido» que as e os habilitam para uma forma específica de ação militante em crescente valorização entre os povos indígenas.

De toda forma, este capital militante advindo com o ingresso na universidade coexiste com uma atuação ligada à aprendizagem tradicional da militância no contexto indígena, especialmente naquilo que as e os jovens indígenas mencionam como um «ouvir os mais velhos» (ou as lideranças tradicionais), no sentido de buscar obter experiências e conhecimentos com aquelas e aqueles que formam parte da história de luta dos povos indígenas. Em paralelo, torna-se importante conceber estas ações militantes como «práticas de resistência estudantil», «contracondutas» e «dispositivos pedagógicos», nas concepções formuladas por Langer e Machado (2013) e Langer (2014), pois possibilitam a visualização dos regimes escolares e universitários de conformação das condutas, assim como das formas de resistir e rebelar-se a eles. E, assim, de (re)colocar-se nas relações de poder instituídas no campo educacional, o que, para os povos indígenas, está imbricado à reprodução da colonialidade do saber (Walsh, 2008).

Uma segunda estrutura de oportunidade política foi a atuação da Fundação Nacional do Índio (Funai), durante os anos de 2003 a 2006, em que conduziu a realização de 88 encontros regionais, com participação de 8650 indígenas de 110 etnias, com foco específico nas temáticas de crianças, adolescentes e jovens indígenas. Os eventos oportunizaram o diálogo intergeracional sobre suas condições de vida, resultando na identificação de «problemas e demandas» similares entre os povos indígenas, assim como o interesse público-estatal da categoria juventude —em conjunto com criança e adolescente- para delineamento de formas de intervenção sócioestatal e articulação interna nos povos indígenas.

Isto culminou, em 2009, na realização do I Seminário Nacional da Juventude Indígena, em Brasília, com apoio organizacional da Funai, e onde houve a emergência da CNJI e da Rejuind, que passam a promover a mobilização político-organizacional das juventudes indígenas em nível nacional. Nesse contexto, pode-se conceber esta ação mobilizatória das juventudes indígenas organizadas dentro do repertório de ações coletivas que perpassam os três tipos básicos definidos por Revilla-Blanco (2010), ainda que, uma vez mais, com forte predominância das ações coletivas contidas, ou seja, de investimento 
na participação de representantes de jovens indígenas em espaços institucionalizados do Estado e de outras organizações sociais indígenas e não-indígenas.

O terceiro fator é o cenário de emergência e desenvolvimento de oportunidades políticas, institucionais e normativas para as juventudes no Brasil, sobretudo a partir de 2005. A «era política» das juventudes como sujeitos de direitos gerou um conjunto de ações sociais e governamentais voltadas ao investimento e à intervenção em pautas ligadas às condições juvenis, o que influenciou o modo como os povos indígenas passaram a discutir esta categoria geracional, assim como as formas de ação e interpelação ao Estado, especialmente no âmbito da participação indígena no Conjuve e nas Conferências Nacionais de Juventude.

No caso do Conjuve, órgão de controle social para planejamento e monitoramento das políticas públicas de juventude, este foi alvo de intensa mobilização das juventudes indígenas para assegurar a participação a partir de 2009. Com isso, objetivando-se ampliar a visibilidade das demandas das juventudes indígenas dentro do rol mais amplo de políticas de juventudes direcionadas ao Estado, mas também na construção de alianças com sujeitos coletivos estratégicos, como as juventudes de povos e comunidades tradicionais e as juventudes rurais, para potencializar as reivindicações e incidência política, o que, certamente, também ampliou as condições de interlocução com o governo e com outros setores das juventudes.

No entanto, este investimento militante na participação dentro do Conjuve foi perdendo centralidade na agenda política das organizações nacionais de juventudes indígenas, sobretudo na CNJI. Isto se deve, por um lado, à própria dificuldade de pautar as questões indígenas dentro das prioridades de atuação do órgão, e, por outro, aos problemas organizacionais das juventudes indígenas, especialmente em relação à falta de apoio financeiro e de déficit de comunicação e articulação interna, que têm prejudicado uma atuação permanente em espaços estratégicos, como no Conjuve.

Em relação às Conferências Nacionais de Juventude, Santos e Yamamoto (2018) indicam que desde a primeira Conferência, realizada em 2008 - portanto, antes da emergência político-organizacional nacional das juventudes indígenas- a pauta das juventudes de povos e comunidades tradicionais, nas quais também se incluem a das juventudes indígenas, aparece como demanda prioritária

na tentativa de se preservar a cultura, linguagem e costumes desses grupos e essa pauta também retorna na III Conferência [em 2015], indicando que essa questão continua sendo 
uma preocupação para a juventude e que mais medidas são necessárias para enfrentar toda e qualquer prática de exploração e discriminação que envolva a juventude de povos e comunidades tradicionais, além de buscar garantir o sustento, a partir da reforma agrária e da regularização da documentação de assentamentos já existentes, como propõe a III Conferência. (2018, p. 661)

Houve a garantia da participação indígena em todas as Conferências Nacionais, o que oportunizou que suas demandas ganhassem a inscrição pública como proposições prioritárias ou relevantes destas Conferências. Porém, como bem demonstram os autores, este processo participativo e de formulação de reivindicações ao Estado, ainda são insuficientes para que sejam canalizadas ou tenham uma centralidade na implantação de políticas públicas. Isto porque, mais do que somente realizar o reconhecimento formal das diversidades, seria preciso construir mecanismos efetivos de ação social e estatal que visassem a transformação do modelo de sociedade baseado nas desigualdades sociais (Santos \& Yamamoto, 2018).

\section{Juventudes indígenas como novíssimo movimento social?}

As lutas antiglobalização e a disseminação dos meios de comunicação digital são marcas do processo histórico do início do século XXI, os quais, segundo Feixa (2016) e Feixa et al. (2009), implicaram reconstrução do campo da ação coletiva e da cidadania, acarretando a emergência de novos tipos de movimentos sociais que os autores vão classificar como novíssimos movimentos sociais. Os autores usam esta tipologia para marcar a distinção entre os novíssimos e os classificados como velhos e novos movimentos sociais, assim como para compreender as marcas de continuidade das estratégias desses dois últimos tipos de movimentos sociais no que passou a se constituir mais recentemente.

Certamente, a CNJI e a Rejuind podem ser classificadas como espaços de materialização do novíssimo movimento social das juventudes indígenas que se apropria de recursos e estratégias dos velhos e novos movimentos sociais, numa interação intergeracional dentro dos povos indígenas, para consolidar sua identidade política e a representação coletiva. Com base em Feixa (2016) e Feixa et al. (2009), é possível empreender a seguinte articulação entre as classificações dos velhos, novos e novíssimos movimentos sociais e o que se identifica na mobilização político-organizacional nacional das juventudes indígenas no Brasil.

Dos elementos que caracterizam os velhos movimentos sociais, um aspecto marcante é o uso dos seminários nacionais —em três edições, ocorridas em 2009, 2012 e 2016, sem- 
pre com a denominação de Seminário Nacional de Juventude Indígena- no sentido de assembléias, identificadas como marca desses velhos movimentos, com a finalidade de formação educacional, debate político e deliberação coletiva sobre os rumos da organização, assim como o uso estratégico da luta militante como instrumento de mobilização e de unidade frente aos antagonistas.

Além disso, a articulação e o engajamento dos jovens junto aos seus povos indígenas se desenvolvem no plano local (da aldeia, da comunidade ou do território local) em que determinado grupo de jovens (militantes ou não) interage com os membros comunitários, expressando suas ideias, modos de vida e demandas, além das formas de mobilização político-organizacional. Segundo mapeamento realizado pelo Cinep (2010), existia, até aquela época, um total de 38 povos indígenas com organizações juvenis.

Logo, a estruturação em grupos locais (Feixa et al., 2009; Feixa, 2016), outra marca dos velhos movimentos sociais, também está presente na mobilização nacional das juventudes indígenas na medida em que compreendem a base local étnica como raiz e compromisso ético-político maior das ações coletivas empreendidas. E mais, todo o processo de constituição de uma organização em escala nacional da juventude indígena foi dependente de etapas prévias de mobilização e organização local das juventudes indígenas, gerando um efeito sequencial de problematizar escalas organizacionais mais amplas (regional, nacional e internacional) para efetividade da incidência política e da interação com outros agentes sociais.

Quanto às características definidoras dos novos movimentos sociais, evidentemente se trata de compreender a mobilização realizada por um segmento geracional de povos indígenas. O movimento geral indígena se encontra enquadrado no rol dos novos movimentos sociais surgidos, no Brasil, a partir da década de 1980, e que tinham (e tem) na demanda por reconhecimento da identidade cultural, um dos elementos fundamentais de sua constituição e ação sociais, haja vista o histórico processo de discriminação étnica. Tal como pontuam Feixa (2016) e Feixa et al. (2009), por estarem inseridos no campo dos movimentos sociais que objetivam a defesa do reconhecimento identitário, são classificados de novos.

No caso da CNJI e da Rejuind, essa reivindicação de reconhecimento identitário continua a ocorrer, mas em dupla dimensão distintiva do âmbito geral dos povos indígenas. A primeira, de reconhecimento pelos próprios povos indígenas, sobretudo às lideranças adultas e às organizações gerais, do valor e da contribuição das juventudes indígenas para as macro-lutas dos povos indígenas por titulação e seguridade territorial, par- 
ticipação social e direitos humanos. Portanto, uma ressignificação identitária intra-étnica antecedida, em alguns povos, pela própria disputa de materialização da categoria juventude como parte do ciclo de vida, mediando tradições culturais e inovações advindas da interação social, especialmente quanto à influência da educação escolar e universitária.

Uma segunda dimensão é do reconhecimento das especificidades identitárias dos indígenas no campo maior de interação com os outros segmentos da juventude nos espaços de participação, especialmente o Conjuve, de modo a por em permanente problematização os universalismos sobre as juventudes que perpassam políticas públicas, ações governamentais e o imaginário social, e que implicam formas de ocultamento ou de inferiorização da pluralidade étnica do «ser jovem», entre outras diversidades sociais. Com isso, está em jogo a capacidade de desconstruir sensos comuns sobre o que é o «ser jovem» e desde que perspectiva os povos indígenas produzem outras simbolizações sobre esta categoria, com o intuito não apenas de apropriação internamente para a classificação e identificação de seus membros, mas também de apontar os caminhos para a incorporação intercultural destas simbolizações, e das reivindicações que elas trazem, nas ações do Estado e da sociedade em geral.

Outro elemento de atuação política utilizado pela mobilização político-organizacional nacional das juventudes indígenas, que se conecta com a classificação dos novos movimentos sociais, é o uso do lúdico, ou do artístico-cultural, para expressar suas formas de fazer política, com especial atenção ao uso estratégico das danças e cânticos culturais indígenas nos espaços de participação junto às juventudes em geral, sendo um momento em que, conforme explica Dinaman Tuxá: «a gente já demarca a nossa presença no local e daí fica difícil deixar de atentar para a nossa voz, a nossa presença» (entrevistado dia 09/05/2016).

Acompanhei representantes das juventudes indígenas durante a $3^{\text {a }}$ Conferência $\mathrm{Na}$ cional da Juventude, ocorrida entre 16 e 19 de dezembro de 2015, em Brasília/DF. Uma das coisas que mais me chamou atenção foi, justamente, o modo como suas ações coletivas tinham sempre por fundamento a visibilidade de uma estética indígena que ressaltava a ética de seus modos de vida e, com isso, de suas militâncias e demandas diferenciadas às políticas e aos direitos das juventudes.

Em vários momentos desta Conferência, os cânticos, as pinturas e as danças colocavam-se como manifestações culturais, mas iam mais além, também se transmutavam em práticas políticas para demarcar o lugar e as identidades culturais das juventudes indígenas no terreno das relações de poder com os segmentos da juventude, possibilitando, 
assim, a articulação direta entre modos de vida juvenis culturalmente diferenciados e formas de reivindicação de direitos.

Por outro lado, estas manifestações apresentam certa politização da alegria, do afeto e do lúdico artístico, tal como pontua Bonvillani (2013), que tem por local de realização o corpo e objetiva estabelecer a encenação pública de imagens, sentimentos e conflitos, de modo a fazer com que «chamem a atenção de todos» e «atraiam os olhares dos nãoindígenas». Isto, por certo, lhes oportunizou, durante a Conferência, angariar adesões políticas às reivindicações e terem maior reconhecimento social de suas falas e formas de expressão do «ser jovem».

Visibilidade, reconhecimento e protagonismo são categorias analíticas que possibilitam entender os significados e as finalidades das manifestações culturais indígenas durante a $3^{\underline{a}}$ Conferência, mas também, de certa forma, da lógica geral de ação militante das juventudes indígenas. Nisso, revela-se uma partilha do sensível, tal como definida por Racière, de «existência de um comum e dos recortes que nele definem lugares e partes respectivas» (2005, p. 15). Nessa existência comum, quem pode tomar parte dela são as e os jovens indígenas, a partir do seu auto-reconhecimento étnico, mas também as e os que se tornam sensíveis a estética das produções indígenas, algo bem perceptível em relação às pinturas, na qual as e os não-indígenas pedem ou pagam para fazê-las, e as e os jovens não se furtam em demarcar nas peles não-indígenas o registro de suas etnicidades, tornando-os mais um «aliado» às causas indígenas.

\section{Juventudes indígenas, internet e redes sociais digitais}

Uma última questão é compreender o entrelaçamento analítico da organização das juventudes indígenas como novíssimo movimento social, tal como propõem Feixa (2016) e Feixa et al. (2009), por meio da forma como sua mobilização nacional emerge «en la frontera entre el espacio físico y virtual» (Feixa, 2016, p. 7).

De modo geral, a internet e as redes sociais digitais têm se convertido em ferramentas de potencialização das lutas sociais, assim como em arena de mobilização e disputa política no/do virtual, com várias funcionalidades instrumentais ao ativismo político juvenil. Subirats indica que com a internet, especialmente na Web 2.o, os

movimientos han sido capaces de generar sus propios contenidos, de propiciar su propia agenda comunicativa, utilizando de manera intensiva las capacidades y potencialidades de las redes sociales y la democratización de los instrumentos de difusión. (2015, pp. 125-126)

Rev.latinoam.cienc.soc.niñez juv. Vol. 18, No. 1, ene.-abr. de 2020 E-ISSN: 2027-7679 http://dx.doi.org/10.1160o/1692715x.18105 
Tal abertura ao espaço virtual tem transformado as formas de deliberação, institucionalidade e discurso político, como bem analisa a autora, encontrando nas juventudes um dos segmentos prioritários de vanguarda de apropriação política das ferramentas tecnológicas e de transformação do político ante o imperativo tecnológico. Nisso, o engajamento e a competência técnica das juventudes para utilização das tecnologias digitais e de fazer política por tais vias, tem se mostrado de enorme importância para reaquecer as formas de ativismo político da juventude. Aqui, comungo da ideia de UribeZapata (2019), de que mais do que propriamente usar a tecnologia (em um sentido passivo e consumista), o que as juventudes estão promovendo é um fazer coisas com ela, num sentido criativo e de apropriação.

O espaço virtual, tal como entendido pelas juventudes indígenas, especialmente aquela organizada na Rejuind, é um território que precisa ser etnicizado ou interculturalizado, para que se transforme num ambiente que oportunize aos indígenas dizerem sua história e confrontarem as narrativas oficiais, de caráter colonial e racista, disseminados por outros meios de comunicação, a educação escolar e a própria internet.

Isto ocorre mediante o uso estratégico da internet para a comunicação entre os pares e para empreender formas inovadoras de visibilização da etnicidade indígena e das reivindicações por direitos para gerar sensibilização e solidariedade de outros segmentos populacionais brasileiros e mundiais, a exemplo do que ocorreu com a campanha de apoio ao povo Guarani-Kaiowá, em 2012, pelo Facebook. (Parágrafo sem sentido)

Com isso, é possivel verificar que apesar das e dos jovens indígenas terem lealdade em relação à base social comunitária, as interações virtuais têm possibilitado a descentralização da articulação política para abarcar tanto elementos nacionais, internacionais e locais, portanto, glocais que, fundamentalmente, tem logrado dar visibilidade e reconhecimento à identidade coletiva de juventudes indígenas forjada nas próprias ações coletivas empreendidas e, tal como observa Revilla-Blanco (2010), oportunizando o fortalecimento da solidariedade e o acesso a aliados de múltiplas escalas geográficas.

As ações coletivas virtuais das juventudes indígenas, especialmente aquelas desenvolvidas pela Rejuind, promovem maneiras mais sustentáveis e crítica de ser e estar no e com o mundo, organizando-se a partir do paradigma da rede similar ao identificado por Uribe-Zapata (2019) em relação as práticas de cidadania emergente de jovens na cidade de Medellín, isto é, de recuperação do espaço público (e, diria, na etnicização do ambiente público virtual), e da insistência na solidariedade e na horizontalidade como 
formas alternativas de organização política e relacionamento social. Em suma, de exercitarem uma novíssima cidadania.

\section{Considerações finais}

O cenário de reflexão sobre a constituição da juventude como causa de interesse público-estatal no Brasil revela oportunidades institucionais, políticas e normativas de importante utilidade para a consolidação da pauta juvenil como prioridade de atendimento por parte do Estado. Além disso, abordar a configuração mobilizatória das juventudes indígenas possibilita identificar cenários de construção de movimentos específicos de significação do «ser jovem» com base no recorte étnico, e que possuem características de novíssimo movimento social, sem deixar de agregar recursos e estratégias dos velhos e novos movimentos sociais, mas, sobretudo, da comunicação intergeracional para aprender a inovar no campo político, numa simbiose entre a atenção às tradições político-culturais dos povos indígenas e a instrumentalização das novas tecnologias de comunicação, sobretudo a internet e as redes sociais digitais.

Porém, nos tempos atuais vividos no Brasil, pós-golpe do impedimento da presidenta Dilma Rousseff, em 2016, e, mais recentemente, com a eleição de governo de extrema direita de Jair Bolsonaro, em 2018, muitas interrogações e dúvidas se colocam para com a continuidade das políticas setoriais de juventude e dos espaços institucionais de participação social. Além disso, há uma tendência de intensificação da agenda neoliberal de exploração de recursos naturais, grande parte localizados em terras indígenas, além do fortalecimento de movimentos de extrema direita que disseminam o ódio contra várias minorias sociais, como os povos indígenas, inclusive com atos de extermínio de pessoas pelo simples fato de serem quem são.

Frente às ameaças de retrocesso no campo das conquistas jurídicas e políticas, os movimentos juvenis e os movimentos indígenas, e particularmente as juventudes indígenas, têm se colocado no desenvolvimento de ações de contestação radical às decisões do atual governo. Isto, em grande parte, demonstra o esgotamento das vias institucionais do Estado para a ação militante, o que pode provocar com que, cada vez mais, às juventudes indígenas só reste a tarefa de resistir ao etnocídio patrocinado pelo Estado brasileiro, buscando, nas poucas políticas que ainda se mantem, sobretudo no campo de acesso à educação universitária, dar continuidade ao fortalecimento de suas capacidades juvenis 
e de disputa por um mundo melhor para as diversidades étnicas do «ser jovem» e de suas coletividades.

Uma agenda de pesquisa sobre a continuidade da mobilização político-organizacional das juventudes indígenas no período posterior a 2016 é importante de ser concretizada, e é meu objetivo também em publicações futuras.

\section{Referencias}

Abramo, H. W. (2011). Condição juvenil no Brasil contemporâneo. Em H. W. Abramo, \& P. P. M. Branco (Orgs.), Retratos da juventude brasileira: análises de uma pesquisa nacional (pp. 37-72). Editora Fundação Perseu Abramo; Instituto da Cidadania.

Bonvillani, A. (2013). Cuerpos en marcha: emocionalidad política en las formas festivas de protesta juvenil. Nómadas, 39, 90-103.

Brasil. (2010). Emenda Constitucional nº 65, de 13 de julho de 2010. Casa Civil.

Brasil. (2018). Decreto nº 9.306, de 15 de março de 2018. Casa Civil.

Centro Indígena de Estudos e Pesquisas. (2010). Informativo Povos Indígenas no Brasil.

Consejo Latinoamericano de Ciencias Sociales, \& Unesco. (2013). Políticas de inclusión social de jóvenes en Latinoamérica y el Caribe: situación, desafíos y recomendaciones para la acción, Informe para la IX Reunión del Foro de Ministros de Desarrollo Social de América Latina y el Caribe. Consejo Latinoamericano de Ciencias Sociales.

Feixa, C. (2016). Pasado y presente: desplazamientos y reconfiguraciones de las generaciones desde la participación política juvenil. Mimeo.

Feixa, C., Pereira, I., \& Juris, J. S. (2009). Global citizenship and the 'new, new' social movements: Iberian connections. Nordic Journal of Youth Research, $17(4), 421-442$. https://doi.org/10.1177/110330880901700405

Fernandes, E. A., Beltrão, J. F., \& Oliveira, A. C. (2015). Povos indígenas, comunidades quilombolas \& ensino superior: a experiência da Universidade Federal do Pará. Em A. C. Oliveira, \& J. F. Beltrão (Orgs.), Etnodesenvolvimento \& Universidade: formação acadêmica para povos indígenas e comunidades tradicionais (pp. 252-280). Editora Santa Cruz.

Freitas, F. S. (2019). Pelo Direito à vida segura: um estudo sobre a mobilização negra pela aprovação do Estatuto da Juventude no Congresso Nacional. Revista Direito e Práxis, $10(2), 1335-1355$. http://dx.doi.org/10.1590/2179-8966/2019/40701

Gohn, M. G. (2014). Manifestações de junho de 2013 no Brasil e praças dos indignados no mundo. Vozes. 
Guaraná de Castro, E., \& Macedo, S. C. (2019). Estatuto da Criança e Adolescente e Estatuto da Juventude: interfaces, complementariedade, desafios e diferenças. Revista Direito e Práxis, 10(2), 1214-1238. http://dx.doi.org/10.1590/2179-8966/2019/40670

Instituto Nacional de Estudos e Pesquisas Educacionais Anísio Teixeira. (2018). Sinopse Estatística da Educação Superior 2017. http://portal.inep.gov.br/censo-da-educacaosuperior

Langer, E. (2014). La biopolítica y los signos de resistencia en estudiantes: entrar, pedir respeto, no fracasar y (en el camino) tener humor. En S. Grinberg, E. Langer, \& I. Pincheira (Comps.), Cuadernos de pensamiento biopolítico latinoamericano (pp. 53-58). Unipe Editorial.

Langer, E., \& Machado, M. (2013). Estudiantes, resistencia y futuro en contextos de pobreza urbana. Polifonías, 2(2), 69-96.

Oliveira, A. C. (2016). Violência sexual, infância e povos indígenas: ressignifcação intercultural das políticas de proteção no contexto das indígenas crianças. Revista Latinoamericana de Ciencias Sociales, Niñez y Juventud, 14(2), 1177-119o. http://dx.doi.org/ 10.11600/1692715x.14220041115

Oliveira, A. C. (2017). Mobilização social de jovens indígenas e a construção intercultural dos direitos da juventude no Brasil. Em: A. C. Oliveira, \& L. H. Rangel (Orgs.), Juventudes indígenas: estudos interdisciplinares, saberes interculturais: conexões entre Brasil e México (pp. 53-77). E-Papers.

Oliveira, A. C. (2019). Contribuições juvenis para os direitos indígenas. Revista Direito e Práxis, 10(2), 1261-129o. http://dx.doi.org/10.1590/2179-8966/2019/40471

Oliveira, A. C., Beltrão, J. F., \& Domingues, W. C. L. (2015). Povos indígenas, ações afirmativas e universidade: conquistas e dilemas da reserva de vagas na Universidade Federal do Pará. História e Diversidade, 6(1), 93-106.

Oliveira, A. C., \& Rangel, L. H. V. (2017). Introdução: juventudes indígenas entre visibilidades e indagações. Em A. C. Oliveira \& L. H. Rangel (Orgs.), Juventudes indígenas: estudos interdisciplinares, saberes interculturais: conexões entre Brasil e México (pp. 13-23). E-Papers.

Poupeau, F. (2007). Dominación y movilizaciones: estudios sociológicos sobre el capital militante y el capital escolar. Ferreyra Editor.

Racière, J. (2005). A partilha do sensivel: estética e política. Editora 34.

Rangel, L. H. V. (2015). Políticas públicas e participação política: juventude indígena na cidade de São Paulo. En S. V. Alvarado, \& P. Vommaro (Comps.), En busca de las condiciones juveniles latinoamericanas (pp. 167-225). Consejo Latinoamericano de 
Ciencias Sociales; El Colegio de la Frontera Norte; Universidad de Manizales; Cinde.

Rede de Juventude Indígena. (2014). A Comissão Nacional da Juventude Indígena. Em Brasil. (Ed.), Juventude e Meio Ambiente (pp. 11-14). Ministério do Meio Ambiente.

Revilla-Blanco, M. (2010). América Latina y los movimientos sociales: el presente de la rebelión del coro. Nueva Sociedad, 227, 51-67.

Rodríguez, E. (2015). Bases para la construcción de un índice de desarrollo de políticas sectoriales de juventud para América Latina. Centro Latinoamericano sobre Juventud.

Santos, L. I. C., \& Yamamoto, O. H. (2018). Juventude brasileira em pauta: analisando as conferências e o estatuto da juventude. Revista Latinoamericana de Ciencias Sociales, Niñez y Juventud, 16(2), 657-668. https://doi.org/10.1160o/1692715x.16201

Silveira, M., \& Veronese, J. R. P. (2015). Normas constitucionais de proteção à criança e ao adolescente: uma questão de eficácia ou de desrespeito? Em J. R. P. Veronese, L. A. Rossato, \& P. E. Lépore (Coords.), Estatuto da Criança e do Adolescente: 25 anos de desafios e conquistas (pp. 115-131). Saraiva.

Subirats, J. (2015). Todo se mueve: acción colectiva: movimientos, partidos e institucionais. RES, 24, 121-131.

Tarrow, S. (1999). Estado y oportunidades: la estructuración política de los movimientos sociales. Em D. McAdam, J. D. McCarthy \& M. N. Zald. (Coors.), Movimientos sociales: perspectivas comparadas (pp. 71-100). Istmo.

Unda-Lara, R. (2016). Guia de la clase 3. Acción colectiva, ciclo político y Estado. Consejo Latinoamericano de Ciencias Sociales.

Uribe-Zapata, A. (2019). Cultura digital, juventud y prácticas ciudadanas emergentes en Medellín, Colombia. Revista Latinoamericana de Ciencias Sociales, Niñez y Juventud, 17(2), 1-19. https://doi.org/10.1160o/1692715x.17218

Vázquez, M. (2013). En torno a la construcción de la juventud como causa pública durante el kirchnerismo: principios de adhesión, participación y reconocimiento. Revista Argentina de Estudios sobre Juventud, 1(7), 1-20.

Verdum, R. (2011). Juventude indígena em situação de risco. Inesc.

Vommaro, P. (2015). Las juventudes movilizadas en América Latina. Em P. Vommaro (Ed.), Juventudes y políticas em la Argentina y em América Latina: tendencias, conflictos y desafios (pp. 57-74). Grupo Editor Universitario.

Waiselfisz, J. J. (2014). Os jovens do Brasil. Secretaria Geral da Presidência da República; Secretaria Nacional de Juventude; Secretaria de Políticas de Promoção da Igualdade Racial. 
Waiselfisz, J. J. (2015). Mapa da violência: mortes matadas por arma de fogo. Secretaria Geral da Presidência da República; Secretaria Nacional de Juventude; Secretaria de Políticas de Promoção da Igualdade Racial. http://www.mapadaviolencia.org.br/ mapa2015.php

Walsh, C. (2008). Interculturalidad, plurinacionalidad y decolonialidad: las insurgencias político-epistémicas de refundar el Estado. Tabula Rasa, 9, 131-152. https://doi.org/ $10.25058 / 20112742.343$ 